\title{
An Analysis of Smart Tourism System Satisfaction Scores: The Role of Priced Versus Average Quality
}

\author{
Jin-Young Kim \\ Kyung Hee University \\ Linda Canina \\ Cornell University
}

Final version published in Computers in Human Behavior (2015), 50, 610-617

Jin-Young Kim, College of Hotel and Tourism Management, KyungHee University, 26, Kyungheedae-ro, Seoul 130-701, Republic of Korea. Corresponding author. Tel.: +82 2961 9454. E-mail: jk293@khu.ac.kr

Linda Canina, School of Hotel Administration, Cornell University, Ithaca, NY 14850, United States. E-mail: 1c29@cornell.edu

This work was supported by a grant from Kyung Hee University (KHU-20111735). 


\begin{abstract}
The availability of customer reviews from smart tourism systems provides an interesting research opportunity to investigate the role of consumer's perceived quality relative to a reference group on online satisfaction scores. This paper shows a positive relationship between the satisfaction score and the difference between the consumers' perceived quality and the reference group's quality level. The findings support comparison-level theory coupled with the product-based norm as a comparison standard, which posits that consumers use the average quality of the product's reference group as the relevant comparison standard. Furthermore, consumers are found to be more sensitive to negative deviations from the reference group's quality than from positive deviations, which is consistent with prospect theory.
\end{abstract}

Keywords: User-generated contents, Hotel industry, Comparison-level theory, Prospect theory 


\section{An Analysis of Smart Tourism System Satisfaction Scores: The Role of Priced Versus Average Quality}

With the development of smart tourism systems, online reviews have become a critical source of information regarding the perceived quality of tourism destinations and hotels (Gretzel \& Yoo, 2008). While the definition of smart tourism is still evolving, it has been generally agreed that smart tourism systems refer to the use of technologies, including but not limited to the internet, mobile communication, and augmented reality to serve the stakeholders of the tourism industry, by providing innovative service and information sharing (Hunter, Chung, Gretzel, \& Koo, 2015; Tu \& Liu, 2014).

For hotels, smart tourism systems have a profound impact on consumers' decisionmaking (Ye, Law, Gu, \& Chen, 2011) because a hotel room is needed irregularly when consumers travel to an unfamiliar place. Furthermore, a fundamental characteristic of hotels is their uniqueness in terms of both physical amenities as well as service level. In particular, architectural qualities, location, age, amenities, customer interaction, as well as service quality are important to guests. Unlike manufactured goods, no two hotels are identical within a product tier (e.g. luxury to economy or five-start to one-star, also referred to as class and category) or even within the same brand. Since many of these characteristics are intangible and are based upon impressions, it is difficult for customers to know ex ante, the physical and the service level quality of the hotel. As a result, the development and utilization of smart tourism systems, where information is generated and shared on blogs, websites, and SNS has been growing rapidly in the lodging and tourism industries.

Online consumer reviews of hotels often describe the quality of the hotel in comparison to the star rating category. A review like "Not worth the four-star rating!' is a typical example. 
In fact, on Tripadvisor.com, one of the largest travel review websites, a keyword of "not star" returns more than 4.94 million hits, which is substantially larger than the number of hits for "'good service', (4.01 million) or "than expected"' (4.07 million) (as of November 2014). Since many reviewers compare their perception of the quality of a hotel to a reference group it is an interesting research topic to investigate how the consumer's perceived quality relative to a reference group of the hotel affects the satisfaction scores in the online space.

Thus, the purpose of this paper is to analyze the relationship between the priced quality of a hotel room relative to the average quality of the reference group and the overall satisfaction score on the smart tourism system. It has been established that price is an important extrinsic cue which serves as a general indicator of quality (Zeithaml, 1988). Thus, we operationalize priced quality of a focal hotel by the agreed-upon paid price given the current perceived quality of the hotel, and the quality of the star rating category by the average price of hotel rooms with the same star rating in the same location, henceforth referred to as the reference group.

The underlying theoretical frameworks for this analysis are comparison-level theory and prospect theory. Comparison-level theory postulates that consumers use comparison levels, or reference points, in order to evaluate the exchange relationship under consideration (Thibaut \& Kelley, 1959). Prospect theory (Kahneman \& Tversky, 1979) also has relevance to this study since consumer satisfaction displays an asymmetric relationship with respect to positive reference group comparisons, gains, and negative reference group comparisons, losses (Mittal, Ross, \& Baldasare, 1998).

This paper extends the existing literature of electronic word-of- mouth (e-WOM) communication and satisfaction in several ways: consumer's relative quality evaluation is analyzed rather than the absolute level; the role of consumer's relative quality gains and their 
relative quality losses are examined; and the estimation procedure corrects for sample selection bias, a methodological problem that has not been addressed much in the existing literature. In addition, this research contributes to the comparison-theory research by using a reference standard that is actually known to be used by consumers.

In the next section, we review the literature in satisfaction and online reviews and develop hypotheses. Instead of going over vast extant literature, we focus on the comparisonlevel theory, prospect theory and e-WOM literature that is most relevant to our hypotheses. Then, we present a description of the sample, the research methodology and results, followed by discussion.

\section{Literature Review and Hypotheses}

Comparison-level theory framework of satisfaction, developed by LaTour and Peat (1979), has been a widely accepted paradigm used to study customer satisfaction in the marketing literature. This theory postulates that satisfaction or dissatisfaction arises through the comparison between a pre-experience standard and the actual experience (LaTour \& Peat, 1979). If the actual experience is better than the referenced standard, customer satisfaction increases whereas if it is less than the referenced standard then satisfaction falls, or dissatisfaction increases.

The unresolved issue in comparison-level theory is the conceptualization and the selection of the comparison standard (Yüksel \& Rimmington, 1998; Yüksel \& Yüksel, 2003). The expectation of the most probable quality has been widely used as a comparison standard. However, researchers have also proposed the use of consumer's prior experience with the brand or similar brands in a product category as the comparison standard (LaTour \& Peat, 1979). 
Along this line, the perceived capability of the overall product category has also been conceptualized as an appropriate reference standard (Woodruff, Cadotte, \& Jenkins, 1983). This reference standard was empirically tested by Cadotte, Woodruff, and Jenkins (1987) in the context of the restaurant industry. In their satisfaction models involving the best brand norm and overall product norm as comparison standards, overall product norm was found to be an appropriate reference standard for fast food and family restaurants whereas the best product norm was more appropriate for upscale restaurants.

While the use of a reference standard based on the product category has valid theoretical and practical support, empirical challenges include the fact that the product class is not always clear. Moreover, consumers' actual comparison mechanism is unobservable. For the lodging industry, these issues are less of a concern. Product tiers or classes are commonly used as reference standards in the lodging industry. Hotels have well-defined product tiers or classes that are officially classified into a diamond or star rating by private and/or public agencies. Furthermore, consumers are familiar with the product tiers and use them as a tangible cue to draw information about the quality (Rao \& Monroe, 1988) of a specific hotel property prior to making the reservation. This evidence is supported further through the guest's online reviews discussed previously.

In terms of the user-generated reviews and ratings, the literature is burgeoning across a broad spectrum of disciplines. The research streams can be categorized according to the following areas: (i) characteristics of the information content; (ii) consumer behavior related to the information generation, search, and the impact on the purchasing decision; and (iii) impact of reviews on firm performance. For example, Kim, Mattila, and Baloglu (2011) identified convenience and quality, risk reduction, and social reassurance as the three main motivating 
factors regarding the information seeking behavior of consumers. Lee and Shin (2014) investigated the characteristics of the online reviews that lead consumers to actually buy the product. They found that visual cues facilitate systematic message processing in addition to the quality of the reviews. Research on the impact of online reviews on firm performance investigated the role of various moderating factors. Zhu and Zhang (2010) found differential impacts of consumer reviews on sales across products in the same product category. They reported that online reviews are more influential for less popular product and for consumers who have greater internet experience.

With regard to the literature related to the smart tourism systems in the lodging industry, Vermeulen and Seegers (2009) found that exposure to online reviews, both positive and negative, enhance consumers' consideration of hotels with a stronger effect for lesser-known hotels. Sparks and Browning (2011) found that positively framed information together with numerical rating details increases both booking intentions and consumer trust, suggesting that consumers tend to rely on easy-to-process information, when evaluating a hotel based upon reviews. Ye et al. (2011) found a significant relationship between online consumer review scores and online booking revenue for hotels.

Racherla, Connolly, and Christodoulidou (2013) and Jeong and Jeon (2008) are among the few that investigated factors that impact online review scores in the lodging industry. In both of these studies, attributes of value and cleanliness were found to be positively associated with the overall satisfaction scores. This paper extends these studies by analyzing the satisfaction rating score from the perspective of a comparison-level framework through the use of the average quality of the star rating category as a reference point. More exactly, this study analyzes the relationship between the overall satisfaction score and a measure of the gap between the 
consumer's evaluation associated with the quality of the hotel and the average value of the reference group. Also, the estimation procedure corrects for sample selection bias.

As discussed above, customer reviews provide anecdotal evidence that product categories are used as reference standards by consumers in the lodging industry. Hotels display a substantial degree of heterogeneity in quality across properties within a star rating category or even within the same brand. Given that hotels are not manufactured, a property's current condition can deviates from its star rating category due to the age of the property, scheduled versus actual maintenance, renovation status, management type, and service (Mattsson, 1992).

Comparison-level theory with the average quality as a reference point predicts that if the hotel property's facilities are old or service is poor compared to what is generally expected for the particular star rating category, customers will feel dissatisfied (Woodruff et al., 1983). On the other hand, if the property is new, just renovated, or provides exceptional service within the star rating category, consumers will feel satisfied. In sum, if the consumer's perceived quality value is above the normative quality level, consumers feel greater satisfaction, and vice versa. Thus, we develop the following testable hypothesis:

H1. Consumer satisfaction with the focal hotel is positively associated with the difference between the perceived quality value and the relevant reference standard of the focal hotel. Prospect theory (Kahneman \& Tversky, 1979) suggests that consumer satisfaction displays an asymmetric pattern with respect to the gains and losses associated with the difference between the perceived quality value and the reference point. In this framework, gains or losses result from a comparison to a reference point; outcomes above this point are regarded as gains while outcomes below this point are treated as losses. Prospect theory asserts that consumers are more sensitive to losses than gains. 
The positive-negative asymmetry is related to the tendency of loss aversion, which means that a one-unit loss is weighted more than an equal amount of gain (Mittal et al., 1998). With satisfaction judgments being reference-dependent (Homburg, Koschate, \& Hoyer, 2005), prospect theory proposes that a one-unit decrease in attribute quality has a larger impact on overall satisfaction than an equal amount of quality increase in the same attribute.

In the service provision, customers will perceive poor service as losses (Zhu, Sivakumar, \& Parasuraman, 2004), which are weighed more heavily in their evaluations of experience according to prospect theory. In the framework of comparison-level theory, it has been reported that negative disconfirmation from the reference point affects more severely on satisfaction than positive disconfirmation does (Anderson \& Sullivan, 1993). McGraw, Larsen, Kahneman, and Schkade (2010) showed evidence of loss aversion when consumers compare and assess gain and losses by a common scale. Thus, the theoretical and empirical literature suggests that when consumers valuate the quality relative to the product-based norm, the negative deviation from the reference point will lead to a greater dissatisfaction than the positive deviation contributes to the satisfaction. In the hotel industry, the star rating categories represent service promises (Ariffin \& Maghzi, 2012), which can serve as a product-based norm for the desired quality. Based on these premises, we postulate the following hypothesis:

H2. A loss that results from a negative difference between the perceived quality value and the norm has a greater impact on the satisfaction scores than the gain. 


\section{Methods}

\section{Data Sources}

The sample of hotels used in this analysis is based on the existing hotels in the Republic of Korea, because the price data and the hotel's identity are published annually for these hotels. Online data were collected from two sources for each of these hotels. Hotel review scores were hand-collected from Hotels.com and Daodao.com by searching individual hotels during the second week of May 2014. The overall review scores from Hotels.com are computed from the reviews submitted to both Hotels.com and Expedia.com because they are both operated by the same parent company, Expedia Inc. According to Expedia (www.expedia.co.uk/daily/information/traveller-opinions/), participating customers rate the hotel on customer's overall satisfaction, the service provided by the hotel staff, the condition of the hotel, and the cleanliness and comfort of the room. Since we are interested in the degree of customer satisfaction, we only retrieved the overall review score from Hotels.com.

Hotels.com is an online intermediary that sells hotel rooms online. Fernandez-Barcala, Gonzalez-Diaz, and Prieto-Rodriguez (2010) pointed out that the intermediary sites, which report review scores and sell hotel rooms at the same time, may inflate the review scores because they have a misalignment of incentives. Thus, in order to avoid any potential bias, we also collected review scores from a non-intermediary site, Daodao.com, which was launched in 2009 as an official site of Tripadvisor in China. Daodao.com was chosen in consideration of the influence of Chinese visitors to Korea. The average of the review scores from these two sites were used for the measure of customer satisfaction in the analysis. The recommendation percentage was also collected from Daodao.com. This is defined as the percentage of participating reviewers who said that they would recommend the hotel to others. 
The credibility of the consumer-generated reviews is a critical issue. In order to warrant trustworthiness, most of the online intermediaries restrict the reviewers to be those who actually booked and stayed at the property. TripAdvisor, which is a pure appraisal site, requires reviewers to register their personal details and imposes penalties for fake reviews (Jeacle \& Carter, 2011).

We also considered the history and the number of reviews available. That is, we included the review score of a hotel only if the number of reviewers exceeds twenty and the written comments date back to at least 2012. These conditions were applied to restrict the final sample to hotels with a sufficient history of available reviews.

The property-level hotel data were collected from the annually published Hotel Industry Operation Statistics 2012 (Korea Hotel Association, 2012), which reports the name of the hotel, the average daily rate (ADR), the number of rooms sold, the occupancy rate, and the revenue per available room (RevPAR) of the participating individual hotel properties in Korea. The ADR is the average paid price for the rooms sold within a year, which is computed by the annual room revenue divided by the number of rooms sold. The RevPAR is the total room revenue divided by the total rooms available. The occupancy rate is the proportion of the rooms sold out of the total number of rooms available. The report also provides the number of customers and the amount of sales revenue by domestic and foreign guests. Chain affiliation can be determined from the name of the hotel.

Several variables can be computed from the dataset. For example, while the number of rooms is not directly provided, it can be computed from the occupancy rate and the number of rooms sold; and the percentage of international guests is calculated by the number of international guests over the number of total guests. The latest report available when this research was conducted was the 2012 issue. While more recent data were desired, we believe 
that the relative quality position of the hotel in the market is stable at least in the short term. The report covers $75 \%$ of hotels in the country.

Hotel ratings, known as the flower system of Korea, are also presented in the report for each hotel property. In Korea hotel ratings are regulated legally by the Tourism Promotion Act and the Enforcement Decree of the Act, unlike in the U.S., where the star or diamond rating systems are not legally defined. All tourist hotels in Korea are rated every three years and classified into five categories, denoted by the number of roses of Sharon, the national flower, by evaluating the lobby, rooms, restaurants, management, parking, safety, and telecommunications facilities, the rating system classifies hotels from five flowers (luxury) to one flower (economy). The report also provides information about hotels newly opened in the middle of the year or shut down during the year. These hotels were excluded from the sample as the performance of the hotel is not comparable to hotels with full-year operation.

Table 1 summarizes the total sample and the review-available sample. After excluding the hotels with partial-year operation, ADR data were available for 442 hotels. Out of these hotels, 120 hotels had the satisfaction score available with a sufficient number of reviews as described above. Clearly, the hotels for which reviews were available show a higher proportion of upper scale properties (51.7\% of properties of luxury and $31.7 \%$ of upper-upscale properties), chain affiliation $(55.8 \%)$, and international visitors $(56.3 \%)$ with higher revenue per available room (RevPAR, USD 102.8). 


\section{Statistical Methods and Variables}

In order to test the established hypotheses, Eqs. (1) and (2) were estimated using Heckman's two-stage estimation procedure that corrects for sample selections bias. Eq. (1) was used to test hypothesis one (H1) and Eq. (2) was used to estimate hypothesis two (H2). These equations were estimated using the overall satisfaction score as a dependent variable. In addition, we also estimated the equations using the recommendation percentage as well. It has long been regarded that revisit intention is extended from satisfaction (Um, Chon, \& Ro, 2006). The overall review score is defined as the average of the review scores from Hotels.com and Daodao.com. The recommendation percentage was obtained from Daodao.com.

$E[$ Satisfaction $\mid$ Satisfaction is observed $]$

$=\beta_{0}+\beta_{1}$ DifferencefromNorm $+[$ HotelRating Dummies $]+\sigma \rho$ Selection

$E[$ Satisfaction|Satisfaction is observed $]$

$=\beta_{0}+\beta_{1}$ DifferencefromNorm $+\beta_{2}$ Loss $+\beta_{3}$ DifferencefromNorm $\times$ Loss + $[$ HotelRating Dummies] $+\sigma \rho$ Selection

There may be a sample selection bias problem as expressed in the conditional form of the dependent variables. The dependent variables are available only for hotels that had a sufficient history of reviews. As a result, the sample is not random. It is possible that properties of certain characteristics were not included in the final sample. If independent variables were excluded from the model that are related to the condition of whether the review score for a hotel is available or not or are correlated with the factors that determine the review score, then the estimated parameters of the equations may be inconsistent (Greene, 2000). 
In order to overcome potential misspecification related to the selection issue, we first ran a Probit regression over all of the properties' data and modeled the probability of a hotel to have the review score available such that $D=f(Z)+u$, where $D=1$ if the review is available and 0 otherwise; $Z$ is a set of explanatory variables that affect the properties to be reviewed in the online space; and $\mathrm{u}$ is an error term. For the explanatory variables, location dummies defined by Seoul, Busan, Jeju Island, and five regional units of Korea (Northwest, Northeast, Central, Southwest, and Southeast), percentage of international visitors among the total guests, chainaffiliation (as an indicator variable), and property size (as a log of number of guest rooms) were included.

Then, in the second stage, the inverse Mill's ratio estimate from the Probit regression was included in Eqs. (1) and (2) as an additional dependent variable, referred to as Selection. Greene (2000) provides technical details of the two stage estimation in the presence of the selection issue, including the derivation of $\rho$ and $\sigma$ in the equations.

The definitions of variables included in the first sage Probit model and the main model are summarized in Table 2. The difference from the norm (Differencefrom, the explanatory variable of interest, was estimated by computing the difference between the price paid for the focal hotel and the average price of the reference group, where the reference group, or Norm, is defined as the group of hotels in the same rating category as the focal hotel and same location.

\section{Insert Table 2 Here}

Specifically, we use the price paid by the consumers, not the quoted price. In the hotel industry, the price paid is referred to as average daily rate (ADR). Marshall (1920) noted early on, that items with similar attributes tend to sell for similar prices in a competitive market. Since ADR is an average of actual room rates accepted by the consumers, it is an indicator of 
customers' value assessment associated with the qualities of a particular hotel. It has been wellestablished that ADR is highly related to the quality and service attributes of a hotel (e.g., Jeong \& Jeon, 2008). If the hotel proposes a price that is not justified by the consumer's value assessment of the quality attributes, the prospective guest will not accept the deal and will search further. From the supplier's perspective, managers also have an incentive to offer a price that is consistent with the current competitive condition of their property since fair behavior is instrumental to the maximization of long-run profits (Rohlfs \& Kimes, 2007).

In order to control for the regional variation in ADR, we constructed the standardized ADR by computing the average ADR of each star rating category by each region and standardizing the difference from the mean by the standard deviation. The location unit was defined by Seoul, Busan, Jeju Island, and five regional units of Korea (Northwest, Northeast, Central, Southwest, and Southeast).

To test Hypothesis 2, an indicator variable Loss and an interaction between Loss and the

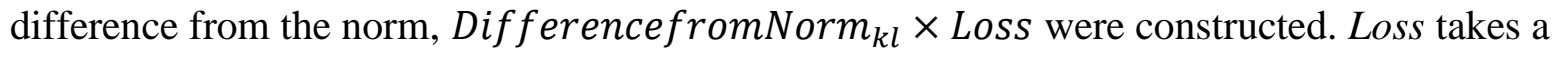
value of one if property i's ADR is below the Norm and zero otherwise. Hotel rating dummies are included as control variables. We labeled five-flower hotels as luxury, four-flower as upperupscale, three-flower as upscale, two-flower as midscale, and one-flower as economy. In the estimation of Eqs. (1) and (2), the dependent variables, the satisfaction score and the recommendation percentage, are censored with the lower bound at zero. Thus, Tobit regression was adopted.

\section{Results}

Table 3 presents the descriptive statistics for the review score and recommendation percentage by product category and the deviation status. Note that this is for the subsample of 
properties with review scores. The column labels "Loss", and "Gain', indicate the group of properties whose ADR was below and above the average ADR of reference group, or Norm, respectively. Overall, the average satisfaction score of the Loss group was 3.77, which was significantly lower than that of the Gain group's average of 3.97. A further look into each star rating category shows that such a difference is driven mainly by the difference in the luxury segment. In other star rating categories, the review scores were lower for the below group, but the differences were not significant.

The satisfaction scores across the different star rating categories are found to be statistically different at the one percent significance level (F-value $=7.36)$. The review score was highest for the luxury segment followed by the upper-upscale and upscale segments. For midscale and economy, the review score was fairly high, but the sample size is too small to draw any meaningful inference.

Table 3 also summarizes the results where the recommendation percentage is the dependent variable. Notice that the results are similar to those of the review score. Overall, the average recommendation percentage is significantly higher for the Gain group (76.18\%) than for the Loss group (69.87\%), which is driven by the luxury segment. The recommendation percentage across the star rating categories are found to be statistically different at the one percent significance level $(F$-value $=4.07)$.

Table 4 presents the Pearson correlation coefficients and the summary statistics for the entire sample and for the sample with review scores. Both review scores and recommendation percentage show a significant positive correlation with the deviation from average (0.26). Rather weak relationships are shown in these correlations which are typical for a differenced variable. Regarding "Having review scores", moderate correlations were found with the star rating 
category (0.63), log of the number of guest rooms $(0.65)$, and the chain affiliation $(0.63)$. The results imply that the hotels included in the online review-available set tend to be big, in terms of the number of rooms, and tend to be upper-class chain affiliated rather than small lower class independent properties. The percentage of international guests is mostly insignificantly correlated with the other variables except for "Having review scores" (0.27), star ratings (0.18), and the log of the number of guest rooms (0.39).

The second stage Tobit regression results are summarized in Table 5. The dependent variable is the overall review score in Models (1) and (2). Model (2) adds the interaction between the DifferencefromNorm and the indicator variable that represents whether this deviation is a gain or a loss. The coefficient of DifferencefromNorm is positive and significant in Model (1), indicating that when the ADR of the focal property is one standard deviation above (below) the average ADR of its star rating category the overall review score increases (decreases) by 0.16 . To lend support to comparison-level theory, the results indicate that as the quality of the hotel moves farther above from the norm, the satisfaction score increases as well.

Model (2) shows that the relationship between the review score and the deviation from the star rating average is significant only for the properties whose priced quality falls below the average of the star rating category. The coefficient of DifferencefromNorm is positive but insignificant in Model (2), but the interaction term is positive and significant. The Wald test confirms that the sum of the coefficients of DifferencefromNorm and DifferencefromNorm $\times$ Loss is significant $\left(X^{2}=10.06\right)$. Thus, when Loss $=1$, the standardized ADR difference has the marginal effect of 0.36 on the review score. In contrast, if Loss $=0$, the marginal effect is 0.09 , but it is insignificant. These results are consistent with prospect theory, which predicts 
asymmetric impact of the gain and the loss on customer satisfaction. ${ }^{1}$ Thus, both Hypotheses 1 and 2 are supported.

Insert Table 3 Here

Insert Table 4 Here

Insert Table 5 Here

The results are similar when the recommendation percentage is used as the dependent variable, as shown by Models (3) and (4) in Table 5. The coefficient of DifferencefromNorm is positive and significant in Model (3). In support of Hypotheses 1, the results show that the marginal effect is 6.40, i.e. one standard deviation above (below) the average ADR of the focal hotel's star rating increases (decreases) the recommendation percentage by $6.40 \%$. Hypothesis 2 is also supported as shown by Model (4). The coefficients of DifferencefromNorm and the interaction term are significant and positive. The results show that those hotels below the norm experience decreases in the recommendation percentage, with the marginal effect of $18.71 \%$. It is also worth commenting that in all estimations, Sigma and Rho were found to be significant at the least at $10 \%$ level, confirming the selection issue. Further, the negative sign of Rho implies that the relationship between the probability of a property being included in the

\footnotetext{
${ }^{1}$ In order to further verify the non-linear relationship, we tested a quadratic specification by including DifferencefromNorm, its squared term, and the star rating categories in the second stage of the estimation. Confirming the non-linear relationship, the coefficient of the squared term was negative and significant for both dependent variables at $10 \%$ level for the average score and at $5 \%$ for the recommendation percentage.
} 
sample and the dependent variable (satisfaction score and recommendation percentage) is negative. It has been reported that dissatisfied consumers more enthusiastically engage in wordof-mouth activities than satisfied consumers (Anderson, 1998). Thus, the results are consistent with this tendency in customer behavior.

\section{Discussion}

Motivated by the ever increasing information on the hotels on the Internet, we investigated the relationship between the satisfaction and the difference from the quality norm. As hypothesized, we found supporting evidence for the relationship between the satisfaction score and the deviation from the average quality of the product class. Further, our analysis was conducted for the hotels with accumulated information available about the true quality. Thus, while we did not directly test, our results suggest that even if expectation on the most probable performance is confirmed, consumers can still feel satisfaction or dissatisfaction, if the performance of the product does not meet the standard implied by the rating category of the hotel. Consistent with prospect theory, the negative deviation was found to have a stronger effect than the positive deviation.

Customers' voluntary reviews and the availability of the systematic aggregation of the individuals' evaluation into a single metric of a satisfaction score in the online space provide refreshed insights into deeper understanding of customer satisfaction. For instance, Enz, Canina, and Lomanno $(2004,2009)$ reported that lower price relative to the peers do not sufficiently boost the occupancy rate to achieve higher revenue. While there has been little subsequent research about why this is the case, the current study provides a possible explanation. It is likely that hotels that offer discount may have inferior attributes compared to the competitors in the 
market. If this is the case, offering discount will not enhance satisfaction or recommendation and therefore does not help increasing revenues.

Similarly, this study also contributes to a clearer understanding of value specifically in the context of hotel product. Consumers tend to associate lower price with a corresponding increase in value (Bojanic, 1996; Zeithaml, 1988), which is positively associated with customer satisfaction and recommendation intention (Kuo, Wu, \& Deng, 2009). However, findings in this study suggest that in the hotel industry lower price within the product tier in a certain geographic boundary does not positively affect the satisfaction scores at least in the online space. For the manufactured goods, it is apparent that lower price for the same product increases value without any ambiguity. Hotels have different characteristics. Considering the heterogeneous nature of hotels in the market, the value definition relevant to the lodging industry appears to be "value is the quality I get for the price I pay" (Zeithaml, 1988), rather than the lower cost for equivalent quality. Nevertheless, in hotel marketing, lower price is often intended to attract customers by compensating the inferior quality and providing better value for money. The regression results suggest that offering discount within the star rating category may not work to boost satisfaction if it is for the poor quality.

This study provides managerial implications as well. For hotels, to a large extent, advertisement and promotion are carried out at the brand level influencing customers' perception toward the brand. However, within a brand, individual hotels have varying qualities. The findings in this study suggest that in order to increase satisfaction, the performance of the property needs to be restored to what is generally accepted for the rating category. Furthermore, in this aspect, the main result of this study is consistent with Hayes and Huffman (1995), who claimed that lowering rates cannot substitute for maintaining high quality. For the managers, it 
should also be noted that the likelihood of having reviews is found to be negatively correlated with the review score. As online media handling information regarding hotels and tourism is flourishing, the managers need to take constant effort to meet and exceed the quality that the property should provide. For the chain operator, the findings in this study confirm the value of maintaining the consistent quality and reputation from the perspectives of the customer satisfaction.

Empirical analysis was conducted carefully in this research. For example, in order to assume that there is no big gap between the pre-purchase expectation and experience, we collected review scores only if a reasonable accumulation of information is available. Still, this study is not without limitations. A more recent dataset for the hotel market properties or time series data for the review score were desired, but not available. While we assumed trustworthiness of the review scores based on the policies imposed by the websites, it is still possible that the reviews are biased in some way. The findings in this study reflect the unique characteristics of the lodging product and consumers' purchasing behavior, and therefore generalizability is not warranted for other industries.

For future research, more dataset will allow a fuller examination of understanding consumer satisfaction in the smart tourism system. For example, by adopting prospect theory, we investigated the asymmetric linear relationship between the deviations from the norm on satisfaction. However, prospect theory further postulates non-linear relationships in each of the satisfaction and the dissatisfaction realm with a greater degree of loss aversion with a bigger loss. Thus, with more dataset, further considerations of satisfied and dissatisfied customer behavior and satisfaction will also be meaningful. 
Table 1. Sample profile.

\begin{tabular}{|c|c|c|c|c|c|c|c|c|c|}
\hline \multirow[t]{2}{*}{ Product tier } & \multicolumn{2}{|c|}{ Total sample } & \multicolumn{2}{|c|}{$\begin{array}{l}\text { Review-available } \\
\text { sample }\end{array}$} & \multirow[t]{2}{*}{ Chain-affiliation } & \multicolumn{2}{|c|}{ Total sample } & \multicolumn{2}{|c|}{$\begin{array}{l}\text { Review-available } \\
\text { sample }\end{array}$} \\
\hline & $N$ & Percent (\%) & $N$ & Percent (\%) & & $N$ & Percent (\%) & $N$ & Percent $(\%)$ \\
\hline Luxury & 72 & 16.3 & 62 & 51.7 & Chain & 77 & 17.4 & 67 & 55.8 \\
\hline Upper-upscale & 72 & 16.3 & 38 & 31.7 & Independent & 365 & 82.6 & 53 & 44.2 \\
\hline Upscale & 142 & 32.1 & 15 & 12.5 & Total & 442 & 100 & 120 & 100 \\
\hline Midscale & 95 & 21.5 & 2 & 1.7 & & \multicolumn{2}{|c|}{ Total sample } & \multicolumn{2}{|c|}{ Review-available } \\
\hline Economy & 61 & 13.8 & 3 & 2.5 & International visitors (\%) & \multicolumn{2}{|c|}{$41.9 \%$} & \multicolumn{2}{|c|}{$56.3 \%$} \\
\hline Total & 442 & 100 & 120 & 100 & $\operatorname{RevPAR}^{\mathrm{a}}$ (USD) & \multicolumn{2}{|c|}{$\$ 53.87$} & \multicolumn{2}{|c|}{ S 102.8} \\
\hline
\end{tabular}

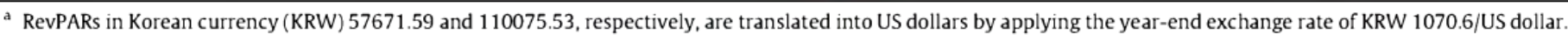


Table 2. List of variables.

\begin{tabular}{|c|c|}
\hline Variable name and description & Description \\
\hline \multicolumn{2}{|l|}{ Dependent variable } \\
\hline \multirow[t]{3}{*}{ Satisfaction score (Satisfaction) } & Average of the review scores from \\
\hline & Hotels.com and Daodao.com for property $i$. \\
\hline & $\begin{array}{l}\text { These sites report the review score on a } 5 \\
\text { point scale }\end{array}$ \\
\hline Recommendation percentage & $\begin{array}{l}\text { Recommendation percentage provided } \\
\text { from Daodao.com (\%) }\end{array}$ \\
\hline \multicolumn{2}{|c|}{$\begin{array}{l}\text { Independent variables in the main model and the Probit model (Data from } \\
\text { Hotel Industry Operation Statistics 2012) }\end{array}$} \\
\hline \multirow{3}{*}{$\begin{array}{l}\text { Difference from the average } \\
\text { rating } k \text { of property } i \text { in } \\
\text { location } l \\
\text { (DifferencefromNorm } i k l)\end{array}$} & $\frac{A D R_{i}-\mu_{U L}}{\sigma_{H}}$, where ADRi is average daily rate \\
\hline & $\begin{array}{l}\text { for the focal property } l, \mu_{k l} \text { is the average } \\
\text { ADR of the star rating } k \text { in location } l \text {, and }\end{array}$ \\
\hline & $\begin{array}{l}\sigma_{k l} \text { is the standard deviation of ADRs of the } \\
\text { hotels of rating } k \text { in location } l\end{array}$ \\
\hline \multirow[t]{2}{*}{ Below the average (Loss) } & 1 if property i's ADR is below the average \\
\hline & $\begin{array}{l}\text { ADR of the properties of the same star } \\
\text { rating in the same location, and } 0 \\
\text { otherwise }\end{array}$ \\
\hline \multirow[t]{2}{*}{ DifferencefromNorm ${ }_{i k l} \times$ Loss } & An interaction term of \\
\hline & Differencefrom Norm $i k i$ and Loss \\
\hline Number of rooms $\left(N_{i}\right)$ & $\log ($ number of rooms for property $i$ ) \\
\hline Chain affiliation $\left(C_{i}\right)$ & $\begin{array}{l}1 \text { if property } i \text { is chain-affiliated, and } 0 \\
\text { otherwise }\end{array}$ \\
\hline Hotel rating dummies & $\begin{array}{l}\text { Indicator variables of luxury (five-flower), } \\
\text { upper-upscale (four-flower), upscale } \\
\text { (three-flower), and midscale (two-flower) } \\
\text { with the economy scale (one-flower) being } \\
\text { the reference group }\end{array}$ \\
\hline Location dummies $\left(L_{i}\right)$ & $\begin{array}{l}\text { Indicator variables of Busan, Jeju Island, } \\
\text { Northwest, Northeast, Central, Southwest, } \\
\text { and Southeast regions with Seoul being } \\
\text { the reference location }\end{array}$ \\
\hline $\begin{array}{l}\text { Percentage of international } \\
\text { guests }\left(\mathrm{ITL}_{i}\right)\end{array}$ & $\begin{array}{l}\text { Number of international guests divided by } \\
\text { the number of total guests }\end{array}$ \\
\hline
\end{tabular}


Table 3. Descriptive statistics.

\begin{tabular}{|c|c|c|c|c|c|c|c|c|c|c|c|c|}
\hline & \multicolumn{2}{|c|}{ Overall ${ }^{*}$} & \multicolumn{2}{|c|}{ Luxury ${ }^{*}$} & \multicolumn{2}{|c|}{ Upper-upscale } & \multicolumn{2}{|c|}{ Upscale } & \multicolumn{2}{|c|}{ Midscale } & \multicolumn{2}{|c|}{ Economy } \\
\hline & Loss & Gain & Loss & Gain & Loss & Gain & Loss & Gain & Loss & Gain & Loss & Gain \\
\hline \multicolumn{13}{|c|}{ (1) Satisfaction score } \\
\hline$N$ & 55 & 65 & 32 & 30 & 19 & 19 & 3 & 12 & - & 2 & 1 & 2 \\
\hline Mean & 3.77 & 3.97 & 3.89 & 4.25 & 3.67 & 3.78 & 3.28 & 3.59 & - & 3.80 & 3.65 & 3.90 \\
\hline St.Dev. & 0.44 & 0.45 & 0.41 & 0.19 & 0.40 & 0.53 & 0.60 & 0.42 & - & 0.28 & $\mathrm{n} / \mathrm{a}$ & 0 \\
\hline Maximum & 4.50 & 4.50 & 4.50 & 4.50 & 4.30 & 4.40 & 3.90 & 4.10 & - & 4.00 & 3.65 & 3.90 \\
\hline Minimum & 2.70 & 2.10 & 3.00 & 3.95 & 2.85 & 2.10 & 2.70 & 2.75 & - & 3.60 & 3.65 & 3.90 \\
\hline \multicolumn{13}{|c|}{ (2) Recommendation percentage } \\
\hline$N$ & 55 & 65 & 32 & 30 & 19 & 19 & 3 & 12 & - & 2 & 1 & 2 \\
\hline Mean & 69.87 & 76.18 & 73.59 & 84.03 & 64.74 & 71.58 & 60.67 & 64.67 & - & 60.00 & 76.00 & 87.50 \\
\hline St.Dev. & 18.17 & 17.50 & 17.07 & 5.56 & 19.16 & 23.04 & 21.73 & 18.41 & - & 28.28 & $\mathrm{n} / \mathrm{a}$ & 0.71 \\
\hline Maximum & 93 & 94 & 93 & 92 & 90 & 94 & 84 & 93 & - & 80 & 76 & 88 \\
\hline Minimum & 25 & 0 & 25 & 70 & 26 & 0 & 41 & 36 & - & 40 & 76 & 87 \\
\hline
\end{tabular}

"* Indicates that the means of the variable by the above and below groups are significantly different at the $1 \%$ level. 
Table 4. Correlation table.

\begin{tabular}{|c|c|c|c|c|c|c|c|c|}
\hline & (1) & (2) & (3) & (4) & (5) & (6) & (7) & (8) \\
\hline Mean & 3.87 & 73.29 & 0.00 & 3.00 & 0.27 & 3.68 & 41.90 & 0.17 \\
\hline (1) Satisfaction score & 1.00 & & & & & & & \\
\hline (3) Difference from norm & 0.26 & 0.26 & 1.00 & & & & & \\
\hline (4) Star rating & 0.35 & 0.22 & -0.00 & 1.00 & & & & \\
\hline (5) Having review score & $\mathrm{n} / \mathrm{a}$ & $\mathrm{n} / \mathrm{a}$ & 0.08 & 0.63 & 1.00 & & & \\
\hline (6) $\log$ (number of rooms) & 0.39 & 0.35 & 0.05 & 0.69 & 0.65 & 1.00 & & \\
\hline
\end{tabular}

$N=442$ for the entire sample, 120 for the sample with the review score and recommendation percentage available. Coefficients of 0.08 and above are significant at $p<0.01$.

a Star rating is coded as an ordinal variable: 1 (economy), 2 (mid-scale), 3 (upscale), 4 (upper-upscale), and 5 (luxury). 
SMART TOURISM SYSTEM SATISFACTION SCORES 26

Table 5. Regression results.

\begin{tabular}{|c|c|c|c|c|}
\hline \multicolumn{5}{|l|}{ (1) Satisfaction score } \\
\hline & \multicolumn{2}{|l|}{ Model (1) } & \multicolumn{2}{|l|}{ Model (2) } \\
\hline & Coefficient & $t$-stat & Coefficient & $t$-stat \\
\hline Intercept $\left(\beta_{0}\right)$ & 3.89 & $18.44^{\cdots}$ & 3.88 & $18.48^{\cdots}$ \\
\hline Differencefrom Norm $\left(\beta_{1}\right)$ & 0.16 & $4.23^{\cdots *}$ & 0.09 & 1.42 \\
\hline Loss & & & 0.09 & 0.80 \\
\hline DifferencefromNorm $\times \operatorname{Loss}\left(\beta_{2}\right)$ & & & 0.27 & $2.07^{*}$ \\
\hline Luxury & 0.20 & 0.93 & 0.27 & 1.24 \\
\hline Upper-upscale & -0.09 & -0.40 & -0.02 & -0.11 \\
\hline Upscale & -0.23 & -0.98 & -0.17 & -0.75 \\
\hline Midscale & 0.28 & 0.80 & 0.33 & 0.96 \\
\hline Sigma & 0.38 & $14.34 \cdots$ & 0.36 & $14.41^{\cdots}$ \\
\hline Rho & -0.64 & $-3.83^{\cdots}$ & -0.59 & $-3.50 \cdots$ \\
\hline \multirow[t]{2}{*}{$R$-squared } & 0.30 & & 0.33 & \\
\hline & & & $\begin{array}{l}\text { Ho: } \beta_{1}+\beta_{2}=0 \\
\chi^{2}=10.06 .\end{array}$ & \\
\hline \multicolumn{5}{|l|}{ (2) Recommendation percentage } \\
\hline & \multicolumn{2}{|l|}{ Model (3) } & \multicolumn{2}{|l|}{ Model (4) } \\
\hline & Coefficient & $t$-stat & Coefficient & t-stat \\
\hline Intercept $\left(\beta_{0}\right)$ & 87.22 & $9.62^{* *}$ & 84.54 & $9.45^{\cdots *}$ \\
\hline Differencefrom Norm $\left(\beta_{1}\right)$ & 6.40 & $4.12^{\cdots}$ & 5.01 & $1.79^{\circ}$ \\
\hline Loss & & & 9.33 & $1.86^{\circ}$ \\
\hline Differencefrom Norm $\times \operatorname{Loss}\left(\beta_{2}\right)$ & & & 13.71 & $2.41^{*}$ \\
\hline Luxury & -7.65 & -0.83 & -4.855 & -0.53 \\
\hline Upper-upscale & -17.29 & $-1.85^{\circ}$ & -14.24 & -1.54 \\
\hline Upscale & -20.42 & $-2.01^{*}$ & -17.68 & $-1.77^{\circ}$ \\
\hline Midscale & -29.60 & $-1.81^{\circ}$ & -25.49 & -1.60 \\
\hline Sigma & 15.80 & $13.87^{\cdots}$ & 15.34 & $14.95^{\cdots}$ \\
\hline Rho & -0.41 & $-2.01^{*}$ & -0.38 & $-1.88^{\circ}$ \\
\hline \multirow[t]{2}{*}{$R$-squared } & 0.23 & & 0.28 & \\
\hline & & & $\begin{array}{l}\text { Ho: } \beta_{1}+\beta_{2}=0 \\
\chi^{2}=14.42 \cdots\end{array}$ & \\
\hline
\end{tabular}

$\cdots p<0.01$

$. p<0.05$

$p<0.1$. 


\section{References}

Anderson, E. W. (1998). Customer satisfaction and word of mouth. Journal of Service Research, $1(1), 5-17$.

Anderson, E. W., \& Sullivan, A. W. (1993). The antecedents and consequences of customer satisfaction for firms. Marketing Science, 12(2), 125-143.

Ariffin, A. A. M., \& Maghzi, A. (2012). A preliminary study on customer expectations of hotel hospitality: Influences of personal and hotel factors. International Journal of Hospitality Management, 31(1), 191-198.

Bojanic, D. C. (1996). Consumer perceptions of price, value and satisfaction in the hotel industry: An exploratory study. Journal of Hospitality \& Leisure Marketing, 4(1), 5-22.

Cadotte, E. R., Woodruff, R. B., \& Jenkins, R. L. (1987). Expectations and norms in models of consumer satisfaction. Journal of Marketing Research, 24(3), 305-314.

Enz, C. A., Canina, L., \& Lomanno, M. (2004). Why discounting doesn't work: The dynamics of rising occupancy and falling revenue among competitors. Cornell University, Center for Hospitality Research.

Enz, C. A., Canina, L., \& Lomanno, M. (2009). Competitive pricing decisions in uncertain times. Cornell Hospitality Quarterly, 50(3), 325-341.

Fernández-Barcala, M., González-Díaz, M., \& Prieto-Rodríguez, J. (2010). Hotel quality appraisal on the Internet: A market for lemons? Tourism Economics, 16(2), 345-360.

Greene, W. H. (2000). Econometric analysis (4th ed.). Upper Saddle River, NJ: Prentice Hall.

Gretzel, U., \& Yoo, K. H. (2008). Use and impact of online travel reviews. Information and Communication Technologies in Tourism, 35-46. 
Hayes, D. K., \& Huffman, L. M. (1995). Value pricing: How low can you go? Cornell Hotel and Restaurant Administration Quarterly, 36(1), 51-56.

Homburg, C., Koschate, N., \& Hoyer, W. D. (2005). Do satisfied customers really pay more? A study of the relationship between customer satisfaction and willingness to pay. Journal of Marketing, 69(2), 84-96.

Hunter, W. C., Chung, N., Gretzel, U., \& Koo, C. (2015). Constructivist research in smart tourism. Asia Pacific Journal of Information Systems, 25(1), 105-120.

Jeacle, I., \& Carter, C. (2011). In TripAdvisor we trust: Rankings, calculative regimes and abstract systems. Accounting, Organizations and Society, 36(4), 293-309.

Jeong, M., \& Jeon, M. M. (2008). Customer reviews of hotel experiences through consumer generated media (CGM). Journal of Hospitality \& Leisure Marketing, 17(1-2), 121-138.

Kahneman, D., \& Tversky, A. (1979). Prospect theory: An analysis of decision under risk. Econometrica, 47(2), 263-291.

Kim, E. E. K., Mattila, A. S., \& Baloglu, S. (2011). Effects of gender and expertise on consumers' motivation to read online hotel reviews. Cornell Hospitality Quarterly, 52(4), $399-406$.

Korea Hotel Association (2012). Hotel Industry Operation Statistics 2012. Korea Hotel Association: Seoul.

Kuo, Y. F., Wu, C. M., \& Deng, W. J. (2009). The relationships among service quality, perceived value, customer satisfaction, and post-purchase intention in mobile valueadded services. Computers in Human Behavior, 25(4), 887-896.

LaTour, S. A., \& Peat, N. C. (1979). Conceptual and methodological issues in consumer satisfaction research. Advances in Consumer Research, 6(1), 431-437. 
Lee, E. J., \& Shin, S. Y. (2014). When do consumers buy online product reviews? Effects of review quality, product type, and reviewer's photo. Computers in Human Behavior, 31, $356-366$.

Marshall, A. (1920). Principles of economics: An introductory volume (8th ed.). Macmillan: London.

Mattsson, J. (1992). A service quality model based on an ideal value standard. International Journal of Service Industry Management, 3(3), 18-33.

McGraw, A. P., Larsen, J. T., Kahneman, D., \& Schkade, D. (2010). Comparing gains and losses. Psychological Science, 21(10), 1438-1445.

Mittal, V., Ross, W. T., Jr., \& Baldasare, P. M. (1998). The asymmetric impact of negative and positive attribute-level performance on overall satisfaction and repurchase intentions. Journal of Marketing, 62, 33-47.

Racherla, P., Connolly, D. J., \& Christodoulidou, N. (2013). What determines consumers' ratings of service providers? An exploratory study of online traveler reviews. Journal of Hospitality Marketing \& Management, 22(2), 135-161.

Rao, A. R., \& Monroe, K. B. (1988). The moderating effect of prior knowledge on cue utilization in product evaluations. Journal of Consumer Research, 15(2), 253-264.

Rohlfs, K. V., \& Kimes, S. E. (2007). Customers' perceptions of best available hotel rates. Cornell Hotel and Restaurant Administration Quarterly, 48(2), 151-162.

Sparks, B. A., \& Browning, V. (2011). The impact of online reviews on hotel booking intentions and perception of trust. Tourism Management, 32(6), 1310-1323.

Thibaut, J. W., \& Kelley, H. H. (1959). The social psychology of groups. Oxford, England: Wiley. 
Tu, Q., \& Liu, A. (2014). Framework of smart tourism research and related progress in China. In A. Kong (Ed.), International conference on management and engineering (CME 2014) (pp. 140-146). DES Tech Publications, Inc.

Um, S., Chon, K., \& Ro, Y. (2006). Antecedents of revisit intention. Annals of Tourism Research, 33(4), 1141-1158.

Vermeulen, I. E., \& Seegers, D. (2009). Tried and tested: The impact of online hotel reviews on consumer consideration. Tourism Management, 30(1), 123-127.

Woodruff, R. B., Cadotte, E. R., \& Jenkins, R. L. (1983). Modeling consumer satisfaction processes using experience-based norms. Journal of Marketing Research, 20(3), 296-304.

Ye, Q., Law, R., Gu, B., \& Chen, W. (2011). The influence of user-generated content on traveler behavior: An empirical investigation on the effects of e-word-of-mouth to hotel online bookings. Computers in Human Behavior, 27(2), 634-639.

Yüksel, A., \& Rimmington, M. (1998). Customer-satisfaction measurement. Cornell Hotel and Restaurant Administration Quarterly, 39(6), 60-70.

Yüksel, A., \& Yüksel, F. (2003). Measurement of tourist satisfaction with restaurant services: A segment-based approach. Journal of Vacation Marketing, 9(1), 52-68.

Zeithaml, V. A. (1988). Consumer perceptions of price, quality, and value: A means- end model and synthesis of evidence. Journal of Marketing, 52(3), 2-22.

Zhu, Z., Sivakumar, K., \& Parasuraman, A. (2004). A mathematical model of service failure and recovery strategies. Decision Sciences, 35(3), 493-525.

Zhu, F., \& Zhang, X. (2010). Impact of online consumer reviews on sales: The moderating role of product and consumer characteristics. Journal of Marketing, 74(2), 133-148. 